\title{
DENTAL FOLLICLE CELL DIFFERENTIATION TOWARDS PERIODONTAL LIGAMENT-LIKE TISSUE IN A SELF-ASSEMBLY THREE-DIMENSIONAL ORGANOID MODEL
}

\author{
J. Chu ${ }^{1}$, O. Pieles ${ }^{2}$, C. G. Pfeifer ${ }^{1,3}$, V. Alt1, ${ }^{1,3}$, C. Morsczeck ${ }^{2}$ and D. Docheva ${ }^{1, *}$ \\ ${ }^{1}$ Laboratory for Experimental Trauma Surgery, Department of Trauma Surgery, \\ University Regensburg Medical Centre, Regensburg, Germany \\ ${ }^{2}$ Department of Oral and Maxillofacial Surgery, University Hospital Regensburg, Regensburg, Germany \\ ${ }^{3}$ Department of Trauma Surgery, University Regensburg Medical Centre, Regensburg, Germany
}

\begin{abstract}
Periodontitis remains an unsolved oral disease, prevalent worldwide and resulting in tooth loss due to dysfunction of the periodontal ligament (PDL), a tissue connecting the tooth root with the alveolar bone. A scaffold-free three-dimensional (3D) organoid model for in vitro tenogenesis/ligamentogeneis has already been described. As PDL tissue naturally arises from the dental follicle, the aim of this study was to investigate the ligamentogenic differentiation potential of dental follicle cells (DFCs) in vitro by employing this 3D model. Human primary DFCs were compared, in both two- and three-dimensions, to a previously published PDLhTERT cell line. The 3D organoids were evaluated by haematoxylin and eosin, 4',6-diamidino-2-phenylindole and F-actin staining combined with detailed histomorphometric analyses of cell-row structure, angular deviation and cell density. Furthermore, the expression of 48 tendon/ligament- and multilineage-related genes was evaluated using quantitative polymerase chain reaction, followed by immunofluorescent analyses of collagen 1 and 3 . The results showed that both cell types were successful in the formation of scaffold-free 3D organoids. DFC organoids were comparable to PDL-hTERT in terms of cell density; however, DFCs exhibited superior organoid morphology, cell-row organisation $(p<0.0001)$ and angular deviation $(p<0.0001)$. Interestingly, in 2 dimensions as well as in 3D, DFCs showed significantly higher levels of several ligamentrelated genes compared to the PDL-hTERT cell line. In conclusion, DFCs exhibited great potential to form PDL-like 3D organoids in vitro suggesting that this strategy can be further developed for functional PDL engineering.
\end{abstract}

Keywords: Periodontitis, periodontal ligament, dental follicle cells, periodontal ligament cell line, scaffoldfree approach, 3D organoids, ligamentogenic differentiation, tissue engineering.

*Address for correspondence: Denitsa Docheva, Laboratory for Experimental Trauma Surgery, Department of Trauma Surgery, University Regensburg Medical Centre, Regensburg, Germany.

Telephone number: +499419431605 Email: denitsa.docheva@ukr.de

Copyright policy: This article is distributed in accordance with Creative Commons Attribution Licence (http://creativecommons.org/licenses/by-sa/4.0/).

\begin{tabular}{llll}
\hline & List of Abbreviations & COL14A1 & collagen type XIV $\alpha 1$ \\
collagen type XV $\alpha 1$ & COL15A1 & cartilage oligomeric matrix protein \\
3D & three dimensional & COMP & 4', 6-diamidino-2-phenylindole \\
decorin & DAPI & desmin \\
APC & aggrecan & actin $\alpha 2$ & dental follicle \\
ASPN & allophycocyanin & DES & dental follicle cell \\
BGN & asporin & DF & Dulbecco's modified Eagle's medium \\
BSA & biglycan & DFC & dimethylmethylene blue \\
CD & bovine serum albumin & DMEM & ethylenediaminetetraacetic acid \\
COL 1 & cluster of differentiation & DMMB & early growth response 1 TF \\
COL 3 & collagen I & EDTA & early growth response 2 TF \\
COL1A1 & collagen III & EGR1 & enzyme-linked immunosorbent assay \\
COL2A1 & collagen type I $\alpha 1$ & EGR2 & ephrin type-A receptor 4 \\
COL3A1 & collagen type II $\alpha 1$ & ELISA & eyes absent homologue $1 \mathrm{TF}$ \\
COL5A1 & collagen type III $\alpha 1$ & EPHA4 & eyes absent homologue 2 TF \\
COL6A1 & collagen type V $\alpha 1$ & EYA1 & flow cytometry analyses \\
COL12A1 & collagen type VI $\alpha 1$ & FACS &
\end{tabular}




\begin{tabular}{|c|c|}
\hline FBS & foetal bovine serum \\
\hline FMOD & fibromodulin \\
\hline FN1 & fibronectin \\
\hline FSC & forward scatter \\
\hline FUT4 & fucosyltransferase 4 \\
\hline GAPDH & $\begin{array}{l}\text { glyceraldehyde 3-phosphate } \\
\text { dehydrogenase }\end{array}$ \\
\hline $\mathrm{H} \& \mathrm{E}$ & haematoxylin and eosin \\
\hline HEPES & $\begin{array}{l}\text { 4-(2-hydroxyethyl)-1- } \\
\text { piperazineethanesulphonic acid }\end{array}$ \\
\hline hTERT & $\begin{array}{l}\text { human telomerase reverse } \\
\text { transcriptase }\end{array}$ \\
\hline IBSP & integrin-binding sialoprotein \\
\hline IgG & immunoglobulin G \\
\hline IQR & interquartile range \\
\hline ITS & internal transcribed spacer \\
\hline$L O X$ & lysyl oxidase \\
\hline$L P L$ & lipoprotein lipase \\
\hline LUM & lumican \\
\hline MEM & minimum essential media \\
\hline$M K X$ & homeobox TF Mohawk \\
\hline MYOD1 & myogenic differentiation 1 \\
\hline MYOG & myogenin \\
\hline NANOG & nanog homeobox pseudogene 8 \\
\hline ODM & osteogenic differentiation medium \\
\hline PBS & phosphate-buffered saline \\
\hline PCR & polymerase chain reaction \\
\hline PDL & periodontal ligament \\
\hline PDL-hTERT & $\begin{array}{l}\text { periodontal ligament-human } \\
\text { telomerase reverse transcriptase }\end{array}$ \\
\hline PE & phycoerythrin \\
\hline PFA & paraformaldehyde \\
\hline PLAP1 & $\begin{array}{l}\text { periodontal ligament-associated } \\
\text { protein } 1\end{array}$ \\
\hline PLOD1 & procollagen-lysine 5-dioxygenase \\
\hline POSTN & periostin \\
\hline POU5F1 & POUdomain, class 5, TF 1 \\
\hline PPARG & $\begin{array}{l}\text { peroxisome proliferator-activated } \\
\text { receptor } \gamma\end{array}$ \\
\hline PRG4 & proteoglycan 4 \\
\hline qRT-PCR & quantitative real-time PCR \\
\hline RT & room temperature \\
\hline RUNX2 & Runt-related TF 2 \\
\hline SCX & scleraxis homologue A TF \\
\hline SIX1 & SIX homeobox $1 \mathrm{TF}$ \\
\hline SIX2 & SIX homeobox $2 \mathrm{TF}$ \\
\hline SOX9 & sex determining region $\mathrm{Y}$ box $9 \mathrm{TF}$ \\
\hline SP7 & Sp7 TF \\
\hline SSC & side scatter \\
\hline TF & transcription factor \\
\hline TFAP2A & adipogenic TF AP- $2 \alpha$ \\
\hline TGF & transforming growth factor \\
\hline TGFB1 & transforming growth factor $\beta 1$ \\
\hline TGM2 & transglutaminase 2 \\
\hline THBS2 & thrombospondin 2 \\
\hline THBS4 & thrombospondin 4 \\
\hline TNC & tenascin $\mathrm{C}$ \\
\hline TNI & tenomodulin \\
\hline
\end{tabular}

\section{Introduction}

Periodontitis is a serious form of periodontal diseases, which is mainly caused by infections and/ or inflammation of the gums. It is a prevalent oral disease, that impairs tooth function and progressively destroys the tooth-supporting structure until tooth loss occurs (Diekwisch, 2016; Oscarsson and
Johansson, 2019; Vo et al., 2020). Epidemiological studies suggest that over $50 \%$ of the adult population is suffering from periodontitis (Romandini et al., 2021). One of the leading consequences of periodontitis is the dysfunction of the PDL, which binds the tooth to the alveolar bone (Benatti et al., 2007; Yao et al., 2008). Therefore, investigating effective and safe PDL therapies fulfils the worldwide oral health need. Currently, the classical therapies, such as scaling and root planning, prevent progression of periodontitis by physically removing the pathogens and necrotic tissue (Park, 2019). However, the PDL can only be partially regenerated at the treated sites (Hernandez-Monjaraz et al., 2018) and the clinical outcome frequently remains unsatisfactory (Chen and Jin, 2010).

A hallmark of tissue engineering-based therapies is to replace the impacted PDL by an engineered PDL-like tissue. Classical tissue engineering is a combining growth factors, biomaterial scaffolds and cells to produce a 3D tissue mimetic (Liu et al., 2015; Raju et al., 2020; Spinell et al., 2019). Alternatively, selfassembly models such as pellet and cell sheet cultures have gained a lot of interest, because they parallel the natural tissue formation process and secure native cell-to-cell and cell-to-matrix interactions, which initiate the appropriate and inherent cell signalling cascades of the used cell types (Yan et al., 2018). Previous studies have shown that mesenchymederived stem/progenitor cells, subjected to pellet and cell sheet culture protocols, were able to produce tenogenic (Hsieh et al., 2018; Yan et al., 2020) and chondrogenic scaffold-free tissues (Pattappa et al., 2019a; Pattappa et al., 2019b).

PDL is considered to arise from a dental follicle within a loose connective tissue sac derived from condensed mesenchyme (Bojic et al., 2014; Felthaus et al., 2014; Sharpe, 2016). The dental follicle surrounds the developing tooth and is present until tooth eruption (Sarrafpour et al., 2013). The derivative PDL is a specialised connective tissue composed of parallel collagen fibres inserting into the root cementum of the tooth on one side and the alveolar bone on the other (Bosshardt et al., 2015). The PDL-specific cells are ligamentocytes that are fibroblastic in nature (Berkovitz, 1990), expressing common tendon/ ligament-related genes (Poschke et al., 2017) and gene markers such as periodontal ligament associated protein-1 (Yamada et al., 2001) and periostin (Horiuchi et al., 1999).

DFCs can be successfully isolated from unerupted and impacted wisdom teeth, which are commonly extracted and disposed of as a medical waste (Morsczeck et al., 2005; Morsczeck and Reichert, 2018). DFCs are reported to be multipotent and to express mesenchymal stem cell markers, such as CD90 and CD105, but not haematopoietic stem cell markers (Liu et al., 2015; Zhou et al., 2019). Moreover, by analysing cloned mouse DFC lines, a profound cellular heterogeneity of the DF has been shown, which may have implication in tissue engineering 
and regenerative strategies (Luan et al., 2006). When comparing three odontogenic progenitor types from dental pulp, PDL and DF for PDL regeneration, Dangaria et al. (2011) reported that the PDL cells were best performing in combination with biomaterials. Several in vitro and in vivo models have further investigated the DFC potential to differentiate towards PDL cells, reporting promising results (Nakashima et al., 2019; Zhang et al., 2019).

In this study, the PDL tissue-forming ability of DFCs was investigated, in comparison to the previously established and characterised PDL-hTERT cell line (Docheva et al., 2010), by using a novel self-assembly 3D organoid model for tenogensis/ ligamentogensis (Hsieh et al., 2018; Yan et al., 2020) and by carrying out detailed histomorphometric, quantitative PCR and protein analyses.

\section{Materials and Methods}

\section{Cell culture}

Commercial human DFCs $(n=6)$ were purchased from AllCells (Alameda, CA, USA). Cells were extracted from impacted wisdom teeth of young (18-25 years old) healthy individuals (N.B. according to AllCells company regulations, further donor information such gender and exact age was not provided to the purchaser). The PDL-hTERT immortal cell line has already been established and characterised (Docheva et al., 2010; Ern et al., 2017; Hsieh et al., 2016; Weider et al., 2020). Both cell types were cultured in low-glucose DMEM (Gibco, Karlsruhe, Germany), supplemented with $10 \%$ FBS and $1 \%$ penicillin (10,000 units/mL) / streptomycin $(10 \mathrm{mg} / \mathrm{mL})$ solution (all from SigmaAldrich). In this study, DFCs were used in passages 4-8 and PDL-hTERT immortal cell line in passages 35-39.

\section{FACS}

DFCs $(n=6)$ were washed in PBS, trypsinised, centrifuged and resuspended in PBS. $5 \times 10^{5}$ cells per donor were incubated with mouse anti-human PE-conjugated CD90 antibody (Cat. No.: 130-095400, Miltenyi Biotec, Bergisch Gladbach, Germany), CD105 APC-conjugated antibody (Cat. No.: 130094-926, Miltenyi Biotec), isotype control mouse IgG1 antibody PE-conjugated (Cat. No.: IC002P, R\&D Systems, Minneapolis, MN, USA) or isotype control mouse IgG2b APC-conjugated antibody (Cat. No.: 130-092-217, Miltenyi Biotec) diluted 1 : 10 in a staining buffer consisting of $2 \mathrm{nmol} / \mathrm{L}$ EDTA, $0.5 \% \mathrm{BSA}$ and $0.01 \% \mathrm{NaN}_{3}$ in PBS. After $45 \mathrm{~min}$ incubation on ice, cells were washed, centrifuged and resuspended again in staining buffer. $2 \times 10^{4}$ events per sample were analysed in a BD FACSCanto II Flow Cytometry System (Becton-Dickinson, San Jose, CA, USA) measuring FSC light, SSC light, PE and APC emitted fluorescence. Data were analysed with Flowing software 2.5.1 (Web ref. 1).

\section{Osteogenic differentiation and alizarin red staining}

DFCs (2 representative donors) were expanded to $80 \%$ confluence in the standard culture medium, then induced by cultivating in ODM composed of high-glucose DMEM (Gibco) supplemented with $2 \%$ FBS, $1 \%$ penicillin/streptomycin, $20 \mathrm{mmol} / \mathrm{L} \mathrm{HEPES}$, $10 \mathrm{mmol} / \mathrm{L} \beta$-glycerophosphate, $100 \mu \mathrm{mol} / \mathrm{L}$ phosphoascorbic acid and $100 \mathrm{nmol} / \mathrm{L}$ dexamethasone (all from Sigma-Aldrich). As a control, cells were cultivated in high-glucose DMEM with $2 \%$ FBS and $1 \%$ penicillin / streptomycin. Medium was changed thrice weekly. After 4 weeks, matrix mineralisation was monitored by classical alizarin red staining was carried out as follows: cells were washed with PBS and fixed in $4 \%$ PFA in PBS for $1 \mathrm{~h}$ and then rinsed $3 \times$ in distilled water. Next, DFCs were incubated in alizarin red solution (Merck Millipore, Darmstadt, Germany) for $20 \mathrm{~min}$, washed $3 \times$ in distilled water and examined using a microscope.

\section{Chondrogenic differentiation and DMMB assay}

DFCs (2 representative donors) were used to form pellet cultures (Pattappa et al., 2019a). Briefly, pellets were formed by centrifuging $2 \times 10^{5} \mathrm{DFC}$ at $215 \times g$ for $5 \mathrm{~min}$ in $300 \mu \mathrm{L}$ chondrogenic medium in V-bottom 96-well plates. The chondrogenic medium consisted of high-glucose DMEM supplemented with $10 \mathrm{ng} / \mathrm{mL}$ TGF-1 (R\&D systems), $100 \mathrm{nmol} / \mathrm{L}$ dexamethasone, $50 \mu \mathrm{g} / \mathrm{mL}$ ascorbic acid-2-phosphate (all SigmaAldrich), $1 \mathrm{mmol} / \mathrm{L}$ sodium pyruvate (Invitrogen) and $1 \%$ ITS (PAN Biotech GmbH, Aidenbach, Germany). As a control, cells were cultivated in the basal medium as described above, without TGF-1. Four weeks after chondrogenic induction, DMMB staining was performed. Pellets were fixed using $4 \%$ PFA in PBS for $1 \mathrm{~h}$, cryoprotected by sucrose gradient and embedded in cryoprotective media (Tissue-Tek, Alphen aan den Rijn, the Netherlands). Cryosections (10 $\mu \mathrm{m}$ thickness) were collected (Leica cryotome, Wetzlar, Germany), and stored at $-20^{\circ} \mathrm{C}$ until use. Prior to staining, sections were equilibrated to room temperature and rehydrated with PBS for 5 min. 3 different cryo-sections per donor were employed and sulphated glycosaminoglycan content was monitored by histochemical staining with DMMB (0.05\% DMMB, $0.5 \%$ ethanol, $0.2 \%$ formic acid, $30 \mathrm{mmol} / \mathrm{L}$ sodium formate, $\mathrm{pH} 3$ ) for $10 \mathrm{~min}$. Sections were then rinsed with distilled water for $30 \mathrm{~s}$, dehydrated by ethanol gradient and xylol, mounted and imaged using a microscope.

\section{Adipogenic differentiation and oil red $\mathrm{O}$ staining}

DFCs (2 representative donors) were seeded and grown in high-glucose DMEM supplemented with $10 \%$ FBS and $1 \%$ penicillin $(10,000$ units/mL)/ streptomycin (10 mg/mL) (all from Sigma-Aldrich) until reaching sub-confluence (> $80 \%)$. Adipogenic differentiation was then induced by using a StemPro Adipogenesis Differentiation Kit (Thermo Scientific, 
Waltham, US) with additional $1 \%$ penicillin/ streptomycin solution (all from Sigma-Aldrich). As a control, cells were cultivated in the basal DMEM medium (all from Sigma-Aldrich). Four weeks after adipogenic induction, oil red $\mathrm{O}$ staining was performed. Cells were washed with PBS, fixed with $4 \%$ formalin in PBS, washed twice with distilled water, and incubated in $60 \%$ isopropanol for $5 \mathrm{~min}$. Cells were then stained for $20 \mathrm{~min}$ with oil red $\mathrm{O}$ working solution from the Lipid (oil red O) Staining Kit (Sigma-Aldrich) according to manufacturer's instructions. Finally, cells were washed thrice with distilled water and imaged using a microscope.

\section{Self-assembly 3D organoid model}

This three-step model is based on a self-assembly of a cell sheet, which is rolled into a 3D rod-like organoid that is subjected to static axial stretch of $10 \%$ and maturation of 2 weeks (Hsieh et al., 2018; Yan et al., 2020). In the first, $2 \mathrm{D}$ expansion, step both cell types were plated into cell culture Petri dish $(100 \mathrm{~mm}$ diameter, Falcon, USA) with a density of $8 \times 10^{4}$ cells $/ \mathrm{cm}^{2}$ until reaching full confluence by day 5 in low-glucose DMEM medium (Gibco) supplemented with $10 \%$ FBS, glutamine $(365.3 \mathrm{mg} / \mathrm{L})$ and $1 \times$ MEM amino acids (all from Sigma-Aldrich), In the second, 2D stimulation, step both cell types were cultured in high-glucose DMEM (Gibco) 10 \% FBS, 1× MEM amino acids and $50 \mu \mathrm{g} / \mathrm{mL}$ ascorbic acid (SigmaAldrich) for $14 \mathrm{~d}$. Afterwards, monolayered cell sheets were detached from the dish using a cell scraper and manually rolled to form approx. 70-80 mm long 3D rod-like organoids. The organoids were transferred to non-adherent culture dishes (Corning, New York, USA), manually stretched by $10 \%$ by fixing using small pins (Ento Sphinx, Pardubice, Czech Republic). In the last, 3D maturation, step the 3D organoids were cultured for $14 \mathrm{~d}$ in maturation medium consisting of high-glucose DMEM supplemented with $10 \%$ FBS, TGF- $\beta 3$ (10 ng/mL), 1× MEM amino acids and $50 \mu \mathrm{g} /$ $\mathrm{mL}$ ascorbic acid. The wet weight of each organoid was measured at day 19 and day 33 (or day 0 and day 14 of the $3^{\text {rd }}$ step). 3D organoids were formed from 6 DFC donors with 5 sheets/donor $(n=6$, replicates 30) and from PDL-hTERT immortal cell line with 5 sheets $(n=1$, replicates 5$)$.

\section{H\&E staining}

DFC ( $n=6,3$ organoids/donor) and 3 PDL-hTERT ( $n=1,3$ organoids) were fixed with $4 \%$ PFA in PBS, cryoprotected by sucrose gradient and embedded in a cryoprotective medium (Tissue-Tek, Alphen aan den Rijn, the Netherlands). Cryosections (10 $\mu \mathrm{m}$ thickness) were collected (Leica cryotome, Wetzlar, Germany) onto glass slides, and stored at $-20^{\circ} \mathrm{C}$ until use. Prior to staining, sections were equilibrated to room temperature and rehydrated with PBS for $5 \mathrm{~min}$. 3 different cryo-sections per sheet were used for H\&E staining (Carl Roth, Karlsruhe, Germany). Sections were placed in haematoxylin solution for $3 \mathrm{~min}$, rinsed with $0.1 \% \mathrm{HCl}$ in $\mathrm{PBS}$ for dedifferentiation and washed in tap water for $5 \mathrm{~min}$. Next, sections were immersed in eosin solution for up to $4 \mathrm{~min}$, rinsed with distilled water for $30 \mathrm{~s}$ and dehydrated by ethanol gradient and xylol and mounted using DEPEX (Serva, Rosenheim, Germany).

\section{Cytohistochemistry}

DFC ( $n=6,1$ organoid/donor) and PDL-hTERT ( $n=1,3$ organoids) groups with 3 cryo-sections per organoid were subjected to further staining. Sections were rinsed in PBS for $5 \mathrm{~min}$. For phalloidin staining, sections were permeabilised with $0.1 \%$ Triton X-100 for $15 \mathrm{~min}$ at RT and incubated with phalloidin-AF594 ( 1 : 200, Cat. No. ab176757, Abcam, Cambridge, UK) for $1 \mathrm{~h}$ at RT. For COL 1 and 3 staining, sections were treated for antigen retrieval with $1 \%$ pepsin for $15 \mathrm{~min}$ at RT. Afterwards, they were blocked with $10 \%$ goat serum (Sigma-Aldrich, Cat. No. SLCD5403) at for $1 \mathrm{~h}$ at RT, and incubated with corresponding primary rabbit anti-human antibodies $(1: 100$, for COL 1 Cat. No. ab34710, COL 3 Cat. No. ab7778, all Abcam) at $4{ }^{\circ} \mathrm{C}$ overnight. Next, goat anti-rabbit secondary cy3-conjugated antibody $(1: 200$, Cat. No. 111-165-144, Jackson ImmunoResearch, Cambridge, $\mathrm{UK}$ ) was given for $1 \mathrm{~h}$ at RT. Sections receiving only secondary antibody served as a negative control. DAPI $(1 \mu \mathrm{g} / \mathrm{mL})$ was used for nuclear counterstaining for $10 \mathrm{~min}$ at RT Representative fluorescence images were taken using an inverted microscope equipped with CCD camera (Carl Zeiss Microscopy, Jena Germany).

For quantitative analysis of COL 1 and 3 fluorescence images, immunostained and imaged sections from DFC ( $n=3,1$ organoid/donor, 1 cryosection per organoid) and PDL-hTERT ( $n=1,3$ organoids, 1 cryo-section per organoid) organoids were evaluated with Image J software (version v1.53d, National Institutes of Health, Bethesda, USA, Web ref.2) as follows.

1. Three images/section (9 images/group) were taken using a $20 \times$ objective lens.

2. Each image was converted into 8-bit grayscale by using "Image-type" tool.

3. By using the "Threshold" tool, the strongly positive stained area was automatically selected and manually adjusted for DAPI and segmented for COL.

4. The "Freehand selections" tool was used to select the region of tissue in each image.

5. In the "Analyze-Set measurements" dialog the parameters "Area", "Area fraction", "Limit to threshold" and "Display label" were set. Then the percentage of COL-positive area was displayed by "analyse-measure" tool.

6. The data were expressed as bar plot with mean and standard deviation for each group where each dot represents each organoid/group.

\section{Cell row structure and angular deviation}

H\&E staining images were used for quantitative analysis of row structure and nuclear angular 
deviation. For the analysis of DFC ( $n=6,1$ organoids/ donor) and PDL-hTERT groups ( $n=1,3$ organoids), per organoid 1 section was investigated and 9 images were taken randomly using a $\times 20$ objective lens on Carl Zeiss Microscope (Jena, Germany) resulting in total of 54 images for DFC group and 27 images of PDL-hTERT group).To analyse cell row structure, on each image, all cell rows were counted with the following assumptions: row with mono-cell-array was defined when the row was composed by a string of individual cells; while multiple-cell-array was defined when the row was composed of strings composed of tightly clustered cells. For nuclear angular deviation, on each image, 9 randomly chosen nuclei were assessed resulting in 486 total nuclei readouts for the DFC group and 243 nuclei readouts for PDL-hTERT group. The angle measurement between the longitudinal axis of the organoid and the major axis of the cell nuclei were determined using the "angular" tool in the ImageJ software.

\section{Cell density analysis}

Cell density was evaluated by quantifying nuclei visualised by DAPI staining and quantifying DAPIpositive area per image. For the analysis of DFC $(n=6$, 1 organoids/donor) and PDL-hTERT groups $(n=1,3$ organoids), per organoid 1 section was investigated. Per organoid, 9 DAPI-stained images taken using a $\times 20$ objective lens were taken randomly resulting in in total of 54 DFC images and 27 PDL-hTERT images. The images were analysed by ImageJ. First each image was converted into 8-bit grayscale by using "image-type" adjustment tool. Next, by using "process-find-edges" tool, the DAPI positive area was automatically highlighted. Last, the percentage of highlighted area was measured by "analysemeasure" tool.

\section{qRT-PCR}

In 2D, DFC ( $n=3)$ and PDL-hTERT ( $n=1,3$ replicates) cells in classical monolayer culture and in $3 \mathrm{D}, \mathrm{DFC}$ ( $n=6,1$ organoid) and PDL-hTERT ( $n=1,3$ replicates) organoids were subjected to qRT-PCR. Total RNA was extracted for each group with RNeasy Mini kit (Qiagen, Hilden, Germany) according to the manufacturer's instructions. For cDNA synthesis, $0.5 \mu \mathrm{g}$ total RNA and Transcriptor First-Strand cDNA Synthesis Kit (Roche, Karlsruhe, Germany) was used. Custom-designed RT-PCR plates containing primers for 48 different genes (Table 1) were used (96-well/32+ format, Bio-Rad Laboratories, Hercules, CA, USA). In addition, mRNA expression levels of CD90 (primer Lot. Nr. qHsaCED0036661), CD105 (qHsaCID0010800), PLAP1 (qHsaCID0023171) and GAPDH (qHsaCEP0041396) and POSTN (forward primer: GCTATTCTGACGCCTCAAAACT; reverse: AGCCTCATTACTCGGTGCAAA) (all primers BioRad) were also analysed. The qRT-PCR reaction was performed using a bioanalyser instrument (BioRad Laboratories) using the following protocol: After 2 min activation at $95^{\circ} \mathrm{C}, 40$ cycles were conducted consisting of denaturation steps for $5 \mathrm{~s}$ at $95^{\circ} \mathrm{C}$ each, and combined annealing/elongation steps for $30 \mathrm{~s}$ at $60{ }^{\circ} \mathrm{C}$ each. Afterwards, melt curve analysis was performed starting at $60^{\circ} \mathrm{C}$ for $1 \mathrm{~min}$ and raising the temperature in $0.3^{\circ} \mathrm{C}$ steps for $15 \mathrm{~s}$ each until $95^{\circ} \mathrm{C}$. Melt temperatures were compared to manufacturer's instructions to check for amplicon specificity. Data from target genes were normalised to HPRT (housekeeping gene) using delta $\mathrm{Ct}$, and compared in fold-change to the PDL-hTERT group.

\section{Statistics}

Independent experimental reproductions are given in the methods and figure legends. GraphPad Prism v8 software (San Diego, USA, Web ref. 3) was used for quantitative data and statistical significance analyses. Quantitative data were shown as: graph bars of mean values and standard deviations, box plot of individual data with maximum, median and minimum values and interquartile range (IQR, 75th-25th percentiles) or violin plot of raw data with median values and IQR. Statistical testing of numeric variable within 2 groups was performed with a nonparametric two-tail $t$-test and multiple $t$-test (Fig. 3b), and categorical variable analyses (e.g. stacked bar plot) was performed with chi-squared test. $p<0.05$ was considered statistically significant.

\section{Results}

\section{Cell morphology and gene expression profile in 2D culture}

Both, DFCs and PDL-hTERT, cell types had fibroblastic morphology with spindle- or triangularlike cell shapes (Fig. 1a). The primary DFCs appeared to occupy larger cell territories than the PDL-hTERT immortalised cells. In order to briefly characterise the DFCs and PDL-hTERT cells in 2D culture, mRNA expression profiling was carried out on 33 different genes related to ligamentogenic lineage as well as multipotency-related 15 different genes representative of adipogenic, chondrogenic, embryogenic, myogenic or osteogenic lineages. The complete gene list, full and abbreviated gene names are given in Table 1 . The obtained heat-map result indicated the expression of multiple ligamentogenic genes in DFC and PDL-hTERT 2D cultures, whilst the majority of the representative genes of the other lineages were undetectable. The following genes were exceptions: $A C A N$ and RUNX2 in DFC group and PPARG, TFAP2A and SOX9 in PDL-hTERT group. Interestingly, DFCs expressed 11 genes significantly higher than PDL-hTERT cells (Fig. 1b). These included EYA2, ACTA2; COL1A1, COL5A1 and COL12A1; $A S P N, D C N, L O X$ and LUM (collagen cross-linking genes) FUT4 and DES. In summary, DFC showed in 2D comparable cell shapes, with a tendency towards larger cell areas. The gene expression profiling revealed great similarity between both groups; however, there was a significant enrichment of 11 
Table 1. List of ligament-related and other lineage genes analysed and gene expression heatmap in 2D culture and 3D organoids. S: significance; Ct scale : high , 2D $<19,3 \mathrm{D}<19$; : expressed, 2D = 19-27, $3 \mathrm{D}=19-28$; : weakly or not detected, $2 \mathrm{D}>27,3 \mathrm{D}>28$. ${ }^{* * *} p<0.01 ;{ }^{* *} 0.01<p<0.03 ;{ }^{*} 0.03<p<0.05$.

\begin{tabular}{|c|c|c|c|c|c|c|c|c|c|}
\hline \multirow[b]{2}{*}{ Annotation } & \multirow[b]{2}{*}{$\begin{array}{l}\text { Target } \\
\text { gene }\end{array}$} & \multicolumn{4}{|c|}{ 2D culture } & \multicolumn{4}{|c|}{ 3D organoids } \\
\hline & & $\begin{array}{l}\text { DFC } \\
n=3\end{array}$ & $\begin{array}{c}\text { PDL- } \\
\text { hTERT } \\
n=3\end{array}$ & $p$ & S & $\begin{array}{l}\text { DFC } \\
n=6\end{array}$ & $\begin{array}{c}\text { PDL- } \\
\text { hTERT } \\
n=3\end{array}$ & $p$ & $\mathrm{~S}$ \\
\hline \multirow{8}{*}{$\begin{array}{l}\text { Ligament-related } \\
\text { transcription } \\
\text { factors }\end{array}$} & EGR1 & & & 0.840 & NS & & & 0.222 & NS \\
\hline & EGR2 & & & 0.516 & NS & & & 0.331 & NS \\
\hline & EYA1 & & & 0.265 & NS & & & 0.084 & NS \\
\hline & EYA2 & & & 0.015 & ** & & & 0.037 & $*$ \\
\hline & $M K X$ & & & 0.646 & NS & & & 0.035 & $*$ \\
\hline & SCX & & & 0.367 & NS & & & 0.176 & NS \\
\hline & SIX1 & & & 0.405 & NS & & & 0.161 & NS \\
\hline & SIX2 & & & 0.364 & NS & & & 0.665 & NS \\
\hline \multirow{7}{*}{ Collagen genes } & COL1A1 & & & 0.034 & * & & & 0.778 & NS \\
\hline & COL3A1 & & & 0.377 & NS & & & 0.017 & $* *$ \\
\hline & COL5A1 & & & 0.048 & * & & & 0.106 & NS \\
\hline & COL6A1 & & & 0.728 & NS & & & 0.364 & NS \\
\hline & COL12A1 & & & 0.041 & * & & & 0.105 & NS \\
\hline & COL12A1 & & & 0.245 & NS & & & 0.054 & NS \\
\hline & COL15A1 & & & 0.087 & NS & & & 0.372 & NS \\
\hline \multirow{9}{*}{$\begin{array}{l}\text { Collagen cross- } \\
\text { linking genes }\end{array}$} & $A S P N$ & & & 0.019 & $* *$ & & & 0.357 & NS \\
\hline & $B G N$ & & & 0.166 & NS & & & 0.403 & NS \\
\hline & $D C N$ & & & 0.005 & $* * *$ & & & 0.069 & NS \\
\hline & $F M O D$ & & & 0.307 & NS & & & 0.319 & NS \\
\hline & $F N 1$ & & & 0.562 & NS & & & 0.137 & NS \\
\hline & LOX & & & $<0.01$ & $* * *$ & & & 0.016 & $* *$ \\
\hline & LUM & & & 0.021 & ** & & & 0.237 & NS \\
\hline & PLOD1 & & & 0.613 & NS & & & 0.752 & NS \\
\hline & TGM2 & & & 0.499 & NS & & & 0.145 & NS \\
\hline \multirow{9}{*}{$\begin{array}{c}\text { Other } \\
\text { ligamentogenic } \\
\text { genes }\end{array}$} & ACTA2 & & & 0.004 & $* * *$ & & & 0.024 & $* *$ \\
\hline & COMP & & & 0.369 & NS & & & 0.546 & NS \\
\hline & EPHA4 & & & 0.857 & NS & & & 0.449 & NS \\
\hline & $P R G 4$ & & & 0.380 & NS & & & 0.302 & NS \\
\hline & TGFB1 & & & 0.386 & NS & & & 0.511 & NS \\
\hline & THBS2 & & & 0.426 & NS & & & 0.441 & NS \\
\hline & THBS4 & & & 0.257 & NS & & & 0.629 & NS \\
\hline & $T N C$ & & & 0.337 & NS & & & 0.031 & $*$ \\
\hline & $T N M D$ & & & 0.264 & NS & & & 0.665 & NS \\
\hline \multirow{3}{*}{$\begin{array}{l}\text { Adipogenic } \\
\text { genes }\end{array}$} & $L P L$ & & & 0.052 & NS & & & 0.884 & NS \\
\hline & PPARG & & & 0.438 & NS & & & 0.076 & NS \\
\hline & TFAP2A & & & 0.245 & NS & & & 0.005 & $* * *$ \\
\hline \multirow{3}{*}{$\begin{array}{l}\text { Chondrogenic } \\
\text { genes }\end{array}$} & $A C A N$ & & & 0.202 & NS & & & 0.239 & NS \\
\hline & COL2A1 & & & 0.311 & NS & & & 0.101 & NS \\
\hline & SOX9 & & & 0.243 & NS & & & 0.288 & NS \\
\hline \multirow{3}{*}{ Embryonic genes } & FUT4 & & & 0.009 & $* * *$ & & & 0.574 & NS \\
\hline & NANOG & & & 0.926 & NS & & & 0.356 & NS \\
\hline & POU5F1 & & & 0.882 & NS & & & 0.930 & NS \\
\hline \multirow{3}{*}{ Myogenic genes } & $D E S$ & & & 0.009 & $* * *$ & & & 0.073 & NS \\
\hline & MYOD1 & & & 0.178 & NS & & & 0.405 & NS \\
\hline & MYOG & & & 0.193 & NS & & & 0.434 & NS \\
\hline \multirow{3}{*}{ Osteogenic genes } & IBSP & & & 0.151 & NS & & & 0.273 & NS \\
\hline & RUNX2 & & & 0.215 & NS & & & 0.096 & NS \\
\hline & SP7 & & & 0.149 & NS & & & 0.428 & NS \\
\hline
\end{tabular}


out of 48 gene transcripts in DFCs, when compared to PDL-hTERT immortalised cell line.

\section{DFC surface marker and PDL-related gene} expression and osteogenic potential In order to further validate the primary DFCs, qRTPCR analysis was performed for the surface gene markers CD90 and CD105, and the PDL-related genes PLAP1 and POSTN revealing significantly higher levels in DFCs, with the exception of POSTN, which was comparable to PDL-hTERT (Fig. 2a). Next, FACS analysis confirmed that all DFC donors were positive for CD90 and CD105 (Fig. 2b). Finally, alizarin red, $\mathrm{DMMB}$ and oil red $\mathrm{O}$ stainings demonstrated that
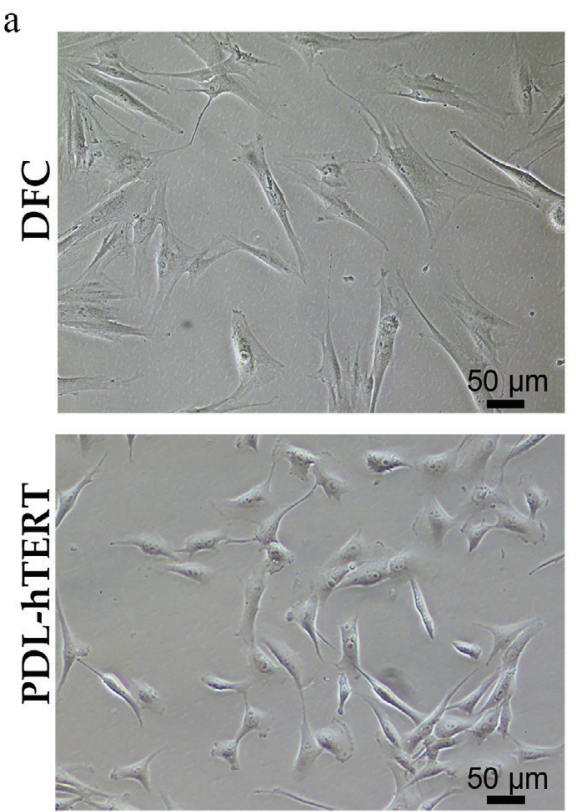

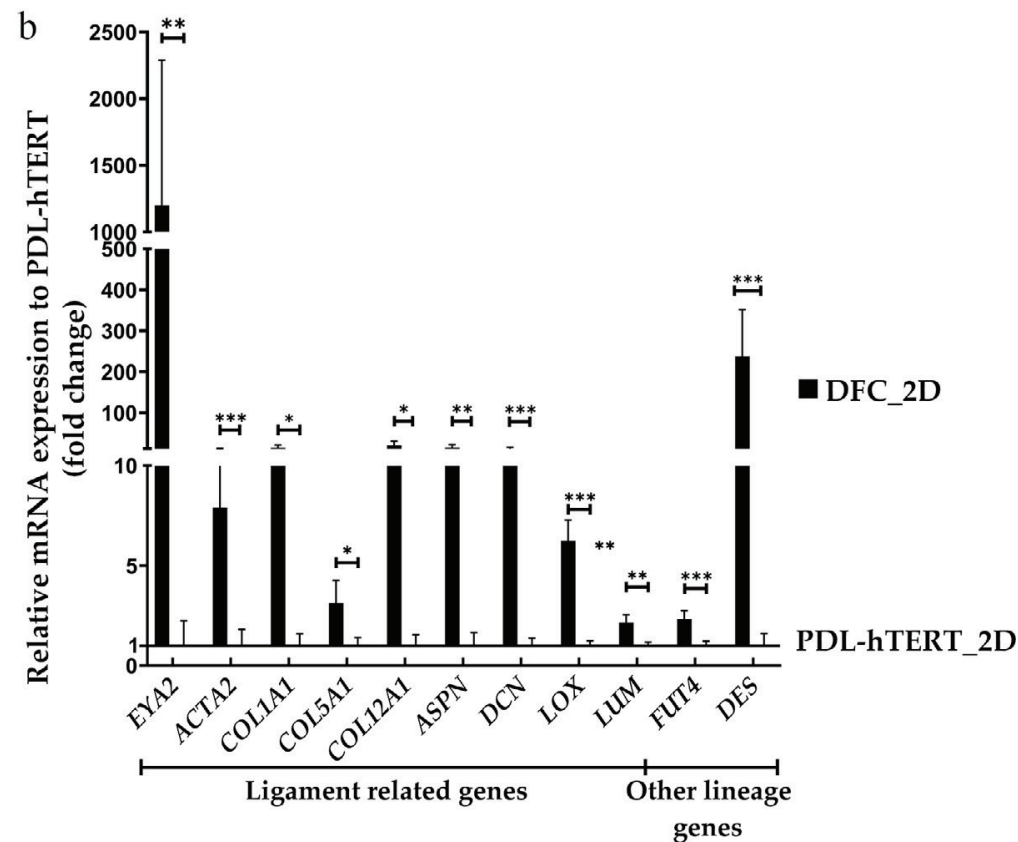

Fig. 1. DFC and PDL-hTERT morphology and gene expression profiling in 2D. (a) Representative phasecontrast images of DFC and PDL-hTERT. (b) qRT-PCR analysis of significantly differentially expressed genes (DFC, $n=3$; PDL-hTERT, $n=1,3$ replicates) in classical monolayer culture. Bar graph, data are expressed as fold-change to PDL-hTERT. The statistical significance was indicated as ${ }^{* * *} p<0.01,{ }^{* *} 0.01<p<0.03$ and ${ }^{*} 0.03<p<0.05$.

$$
\text { }
$$
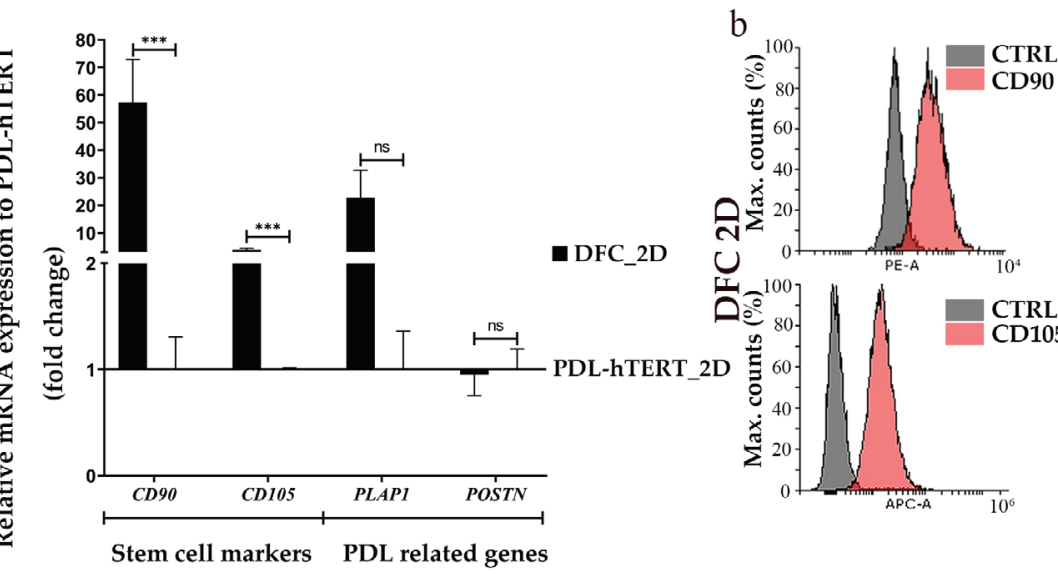

Alizarin Red
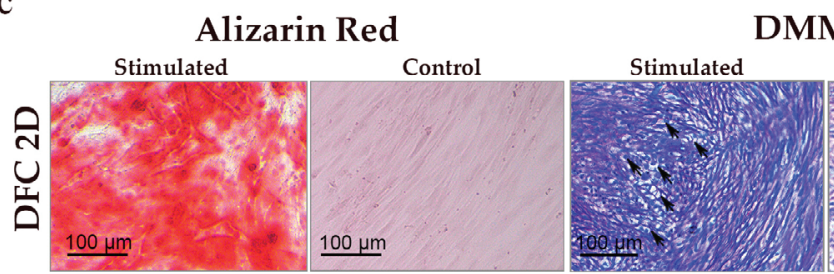

DMMB

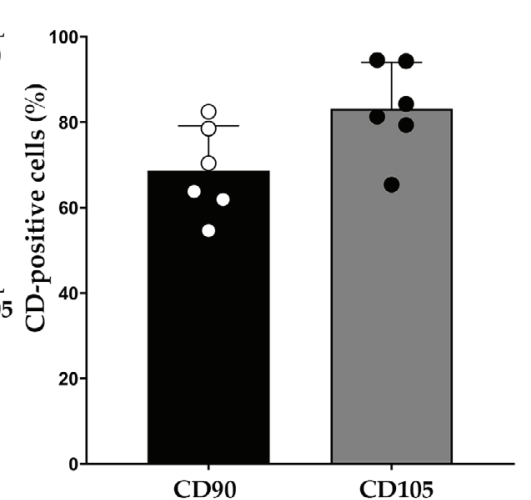

Fig. 2. DFC validation in 2D. (a) Gene expression of CD90, CD105, PLAP1 and POSTN by qRT-PCR (DFC, $n=3$; PDL-hTERT $n=1,3$ replicates) in classical monolayer culture. Bar graph, data are expressed as fold-change to PDL-hTERT. The statistical significance was indicated as ${ }^{* * *} p<0.01,{ }^{* *} 0.01<p<0.03$ and ${ }^{*} 0.03<p<0.05$. (b) Representative FACS histograms for CD90 and CD105 and quantification of CD-positive cells (in percentage, $n=6$ ). (c) Representative images of alizarin red, DMMB and oil red $\mathrm{O}$ stainings of stimulated DFC and unstimulated controls $(n=2)$, the black arrows indicate chondrocytes and stained lipid vacuoles. 
DFCs were capable of trilineage differentiation following $28 \mathrm{~d}$ of stimulation (Fig. 2c).

\section{Gross appearance and wet weight analysis of} DFC and PDL-hTERT 3D organoids

Fig. 3a illustrates the organoid manufacturing protocol with the time needed for each step. Both cell types were $100 \%$ successful in forming 3D organoids. At the beginning of the $3^{\text {rd }}$ (maturation) step, DFC organoids were significantly heavier (Fig. $3 \mathbf{b}, p=0.0419)$ than PDL-hTERT organoids. After $14 \mathrm{~d}$ of maturation, the organoids of both groups significantly contracted ( $p=0.0004$ in DFC group; $p=0.0019$ in PDL-hTERT group) and reached comparable wet weight (Fig. 3b, $p=0.173$,).

\section{Histomorphometry of DFC and PDL-hTERT 3D organoids}

H\&E staining (Fig. 4a) was employed to analyse the tissue morphology of the 3D organoids. In general, DFC formed more organised organoids with wellaligned rows containing elongated cells, while PDL-hTERT organoids demonstrated large rows of columned/clustered cells and a more disorganised matrix (Fig. 4a). Next, analyses of cell row numbers and structure (Fig. $4 \mathbf{b}, \mathbf{c}$ ) revealed that DFC organoids contained more cell rows that PDL-hTERT. Furthermore, their rows were mainly composed of mono-cell-arrays, while PDL-hTERT organoids contained high incidence of rows with multi-cellarrays (Fig. 4c). The superior cell alignment in the DFC group was further confirmed by quantitative investigation of nuclear angular deviation (Fig. 4d,c). In the DFC group, $75 \%$ of the nuclei deviated in the range $0.01-18.05^{\circ}$ angles from the axial axis of the organoids, while in the PDL-hTERT group, $75 \%$ of the nuclei ranged from $0.65-40.12^{\circ}$ angles (Fig. $4 \mathbf{d}$ ). The mean nuclear angular deviation of the DFC group was $9.56^{\circ}$, which was significantly lower compared to the PDL-hTERT group, with mean nuclear angular deviation of $19.8^{\circ}$ (Fig. $4 \mathrm{~d}, p<0.0001$ ). In contrast, no significant difference was detected with regards to the cell content of the organoids from both groups, which was evaluated by DAPI nuclear staining and quantification of DAPI-positive area (Fig. 5a-c). In the DFC group, $11.42 \%$. of the organoids were occupied by DAPI-positive nuclei, which was comparable to the PDL-hTERT group $11.66 \%$ (Fig. 5b,c). Finally, phalloidin fluorescent staining for F-actin revealed robust actin stress fibres and suggested cell-cell contacts in the cell rows in both groups. Yet again, a well-aligned cellular pattern was visible in the DFC

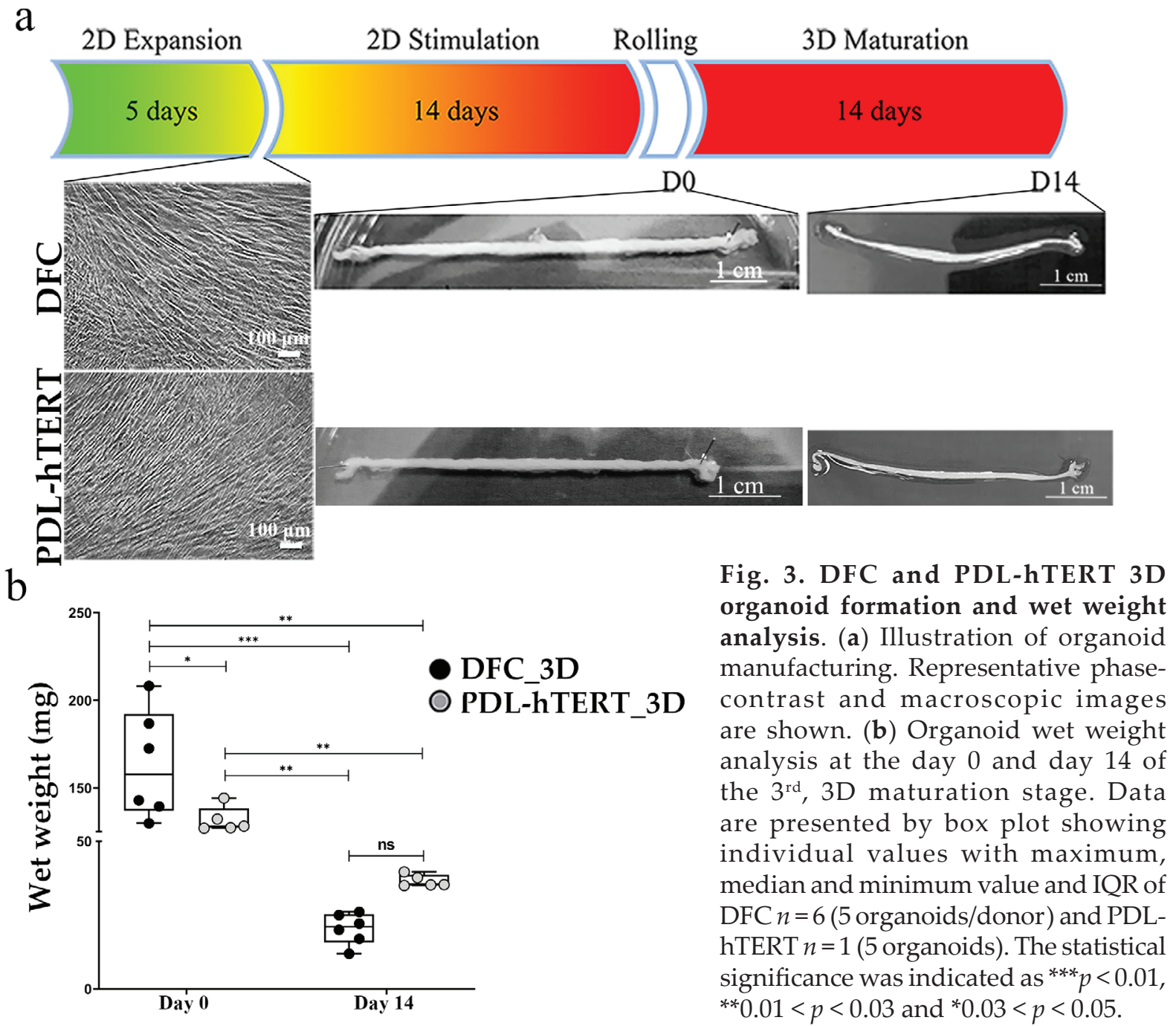


organoids, in contrast to more columned/clustered arrangement of cells in PDL-hTERT organoids (Fig. 5d). Altogether, the detailed histomorphometry presented significantly better tissue morphology of the DFC organoids versus those formed by the PDLhTERT immortalised cell line.

\section{Comparison of gene expression of DFC and PDL- hTERT 3D organoids}

Similar to the analysis of the 2D cultures, both types of 3D organoids were subjected to a comprehensive gene expression profiling of the same 48 different genes and the PDL-specific PLAP1 and POSTN genes. Interestingly, the heat map result (Table 1) suggested that there is no expression (a part of TFAP2A in PDL-hTERT group RUNX2 in both groups) of the genes related to multipotency in the
3D organoids, which suggests ligamentogenic lineage restriction in the 3D model. Yet again, screening for significantly differentially expressed genes revealed higher expression levels of EYA2, MKX and COL3A1 in the DFC 3D organoids (Fig. 6a). Oppositely, ACTA2, TNC, LOX and TFAP2A were significantly downregulated in DFCs compared to PDL-hTERT organoids (Fig. 6a). Furthermore, PDL-hTERT organoids showed a comparable expression of PLAP1 and POSTN between the two groups (Fig.6a). Finally, immunofluorescent staining for 2 critical matrix proteins in PDL, namely COL 1 and COL 3, confirmed their abundant deposition in the extracellular matrix of the organoids. Analysis of fluorescence microscopy images suggested a higher expression level of COL1 in the PDL-hTERT organoids ( $p=0.0252)$, while DFC organoids exhibited a higher expression a

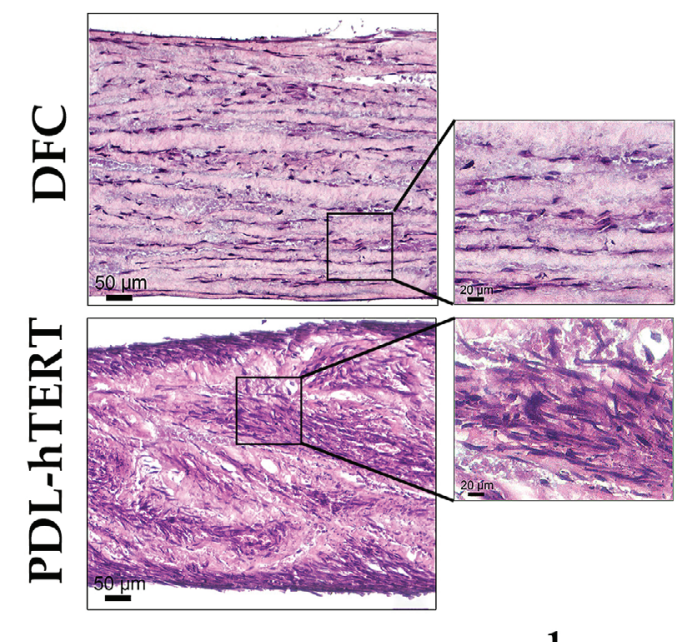

C

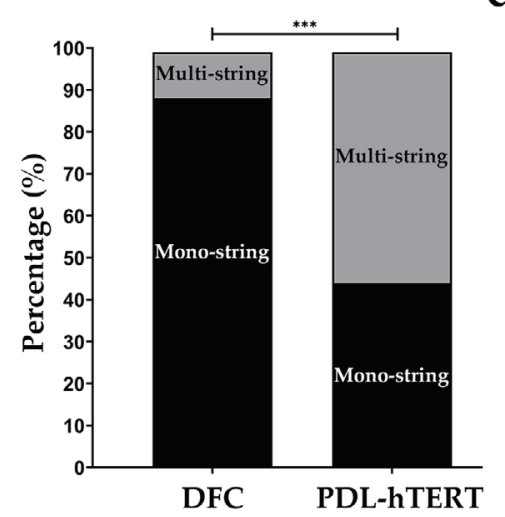

b

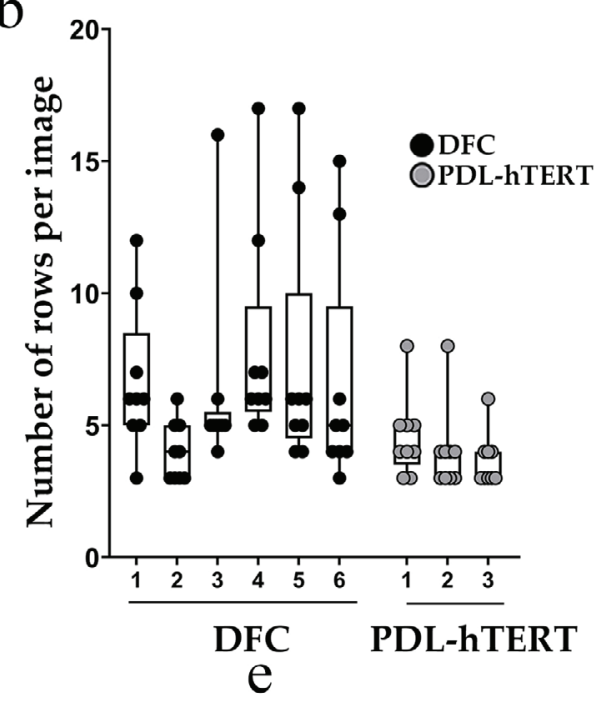

Fig. 4. H\&E staining and histomorphometry of the DFC and PDL-hTERT 3D organoids. (a) Representative H\&E images of DFC ( $n=6,3$ organoids/donor) and PDL-hTERT ( $n=1,3$ organoids) organoids. (b) Box plot showing the number of rows per analysed image of both DFC $(n=6,1$ organoid/donor; 1 section/organoid; 9 different images/organoid; in total 54 images analysed) and PDL-hTERT ( $n=1,3$ organoids, 1 section/ organoid; 9 different images/organoid; in total 27 images analysed) organoids. (c) Bar graph showing, in percentage, the ratio between rows structured as mono-cell-array or multi-cell-array in DFC and PDL-hTERT organoids. (d) Violin plot showing raw data (median, IQR, min. and max. values) of cell angular deviation of DFC ( $n=6$, 1 organoid/donor; 1 section/organoid; 9 different images/section; 9 cells/image; in total 486 data points) and PDL-hTERT ( $n=1 ; 3$ organoids; 1 section/organoid; 9 different images/section; 9 cells/image; in total 243 data points). (e) Mean angular deviation (bar graph with mean values and standard deviation) of DFC and PDL-hTERT organoids. 
levels of COL 3 ( $p=0.0099)$; however, these findings require validation using western blotting or ELISA in follow up studies. Taken together, similar to the 2D condition, the gene expression profiling of DFC 3D organoids was largely comparable to that of PDLhTERT organoids with the exception of 11 different genes, which showed a significant difference between the 2 groups.

\section{Discussion}

DFCs are the developmental precursor cells for the periodontium, including cementum, PDL and alveolar bone. (Saugspier et al., 2010). DFCs, therefore, draw a great interest in PDL tissue engineering. Sowmya et al. (2015) reported that DFCs exhibited a good proliferation ability and in vitro differentiation potential towards cementoblasts, fibroblasts and osteoblasts. Guo et al. (2018) demonstrated, in an in vivo rat model, that co-transplantation of DFCs with Hertwig's epithelial root sheath cells, loaded onto inactivated dentine matrix, resulted in the formation of cementum and PDL-like tissues.

In the current study, primary DFCs and the PDL-derived cell line were first compared in classical 2D culture and the gained results revealed a comparable expression pattern of multiple ligamentogenic genes as well as the PDL-associated gene POSTN. Interestingly, 2D DFCs exhibited a higher expression levels of several COLs. Although DFCs are a promising cell target for PDL engineering and regeneration, the development of an effective therapeutic approach remains critical for the use of DFCs in clinical applications.

The self-assembly cell sheet-based models for PDL have drawn attention, because they are based on the formation of tight mono-layer of cells, containing a
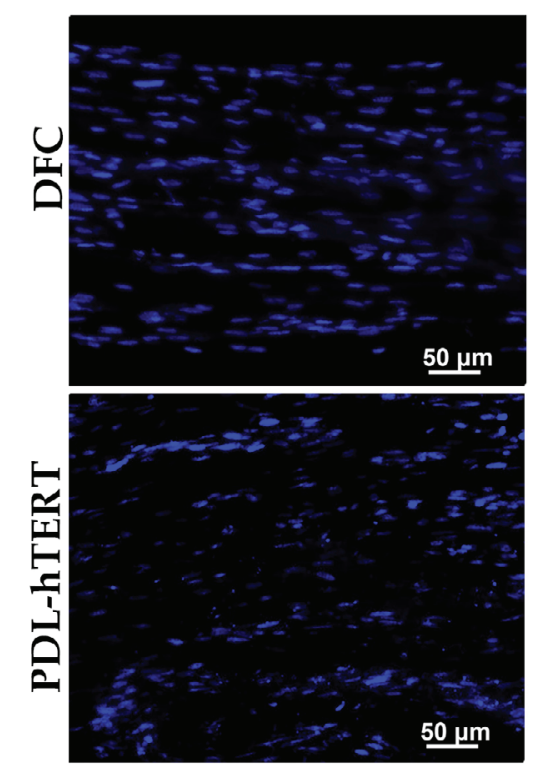

C

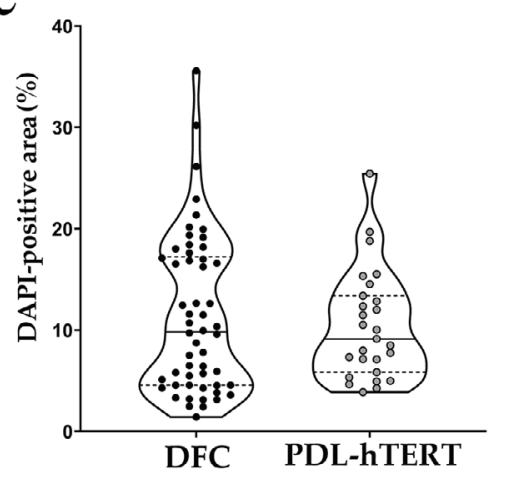

b

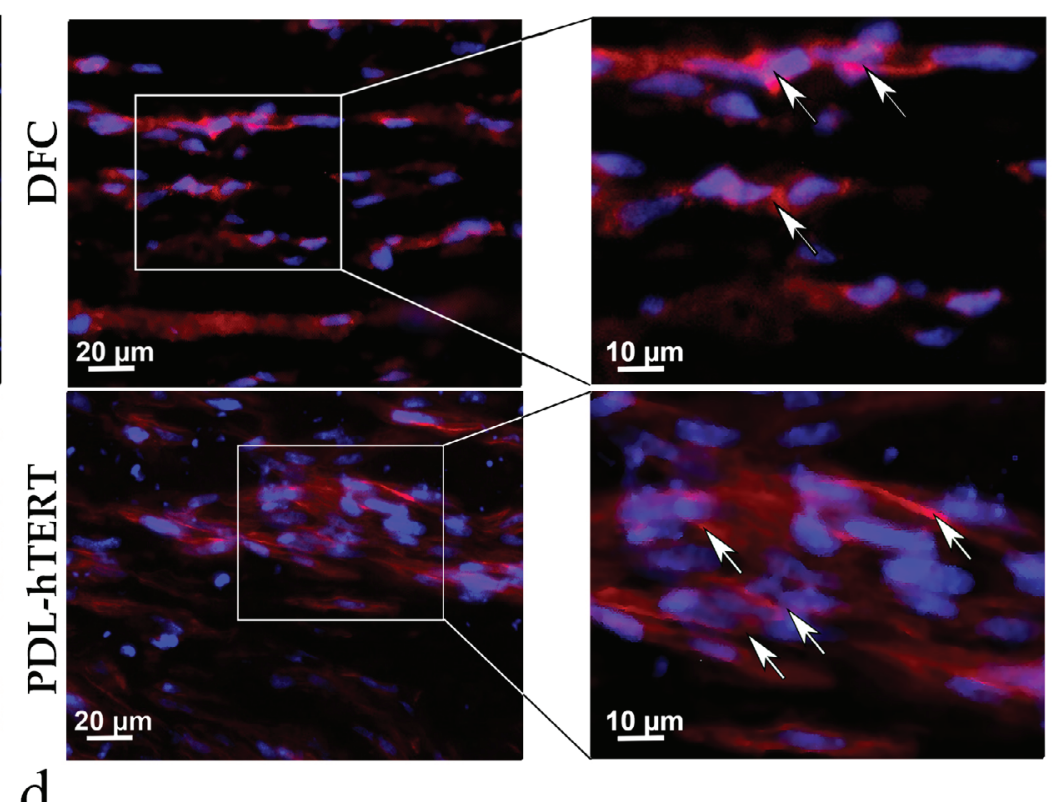

$\mathrm{d}$

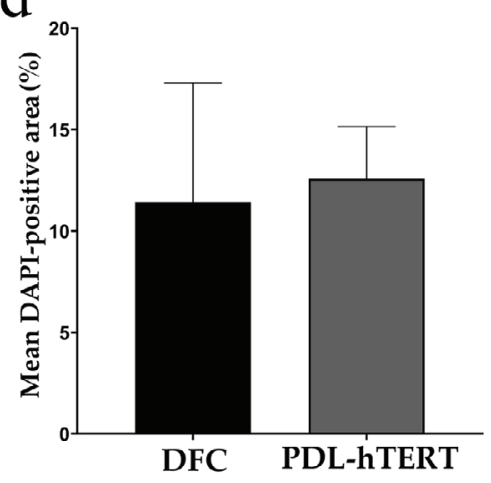

Fig. 5. Nuclear and F-actin staining of the 3D DFC and PDL-hTERT organoids. (a) Representative DAPI images of both DFC ( $n=6,3$ organoids/donor) and PDL-hTERT ( $n=1,3$ organoids) organoids. (b) Representative images of F-acting staining. White arrows indicate robust actin fibres. (c) Violin plot showing raw data of DAPI-positive area in DFC ( $n=6,1$ organoid/donor; 1 section/organoid; 9 different images/ organoid; in total 54 images analysed) and PDL-hTERT ( $n=1,3$ organoids; 1 section/organoid; 9 different images/organoid; in total 27 images analysed) organoids. (d) Bar graph of mean values and standard deviation of DAPI-positive area in DFC and PDL-hTERT organoids. 
native cell-cell and cell-matrix interactions; are free of natural or synthetic carriers; and have been suggested to be more efficient than injection of cell suspensions (Basu et al., 2019; Xu et al., 2019; Yang et al., 2019b). Guo et al. (2013) were first to establish a DFC cell sheet model and reported several advantages of DFCs versus PDL-derived cells, such as producing richer matrix, having higher gene expression levels and demonstrating stronger regeneration of periodontium in vivo. Furthermore, when combined with treated dentine matrix, DFCs exhibited great potential in periodontal regeneration in a one-wall periodontal intrabody defect model in beagle dogs (Yang et al., 2019a).

In the current study, 3D organoid model for ligamentogenesis (Hsieh et al., 2018; Yan et al., 2020) were employed that differed from the cell-sheet models in the following aspects.

1. The initially formed monolayer cell sheets were, not only detached from culture dishes, but also rolled up 70-80 $\mathrm{mm}$ long, 3D rod-like tissue structures.
2. The organoids were subjected to $10 \%$ static axial stretch in order to induce mechanical stimuli.

3. The organoids were supplied with pro-tenogenic/ ligamentogenic growth factor TGF- $\beta 3$.

In general, the current study is in line with previous literature. Specifically, the detailed histomorphometry analyses revealed that DFC organoids were superior in terms of cell-row numbers and composition as well as cell alignment when compared to the PDLhTERT organoids. Besides, DFC organoids showed significantly higher expression of the developmental tenogenic/ligamentogenic transcription factors EYA2 and MKX as well as COL 3. MKX has been reported to play an important role in tendon/ligament development, including PDL, and control over collagen fibrillogenesis (Koda et al., 2017). Although the main collagen fibres of the PDL consists of COL 1 , fibres that are made up by other collagen (e.g. COL 3) are also contained in this tissue (Kono et al., 2013). The immunohistochemistry data successfully validated the abundant protein expression of COL 1 and 3 at the protein level in the DFC organoids. Hence, by direct

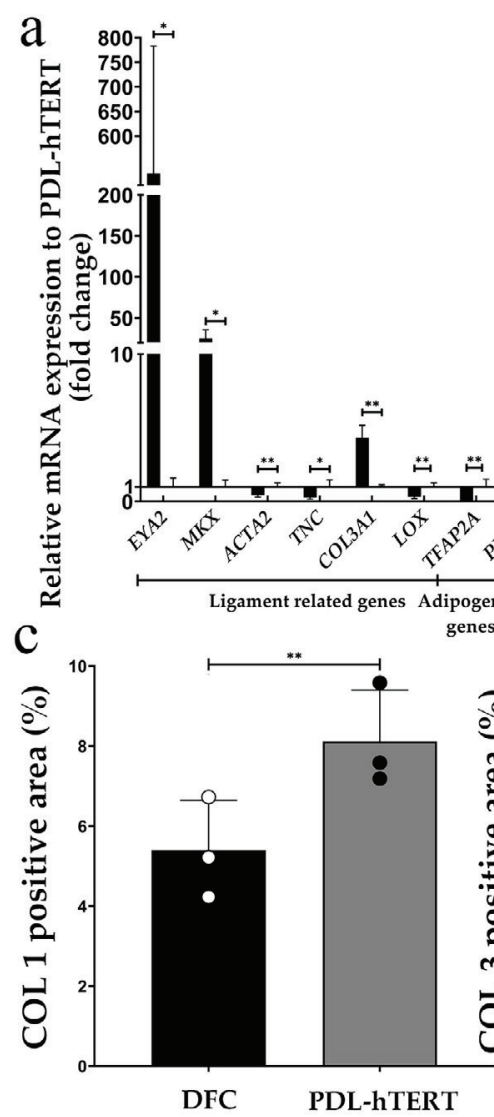

b

DFC

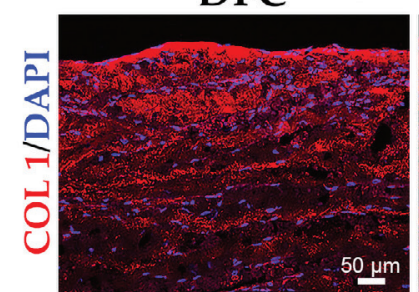

$50 \mu \mathrm{m}$

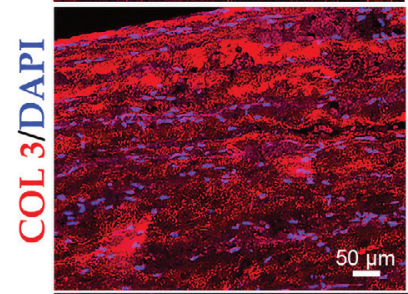

PDL-hTERT
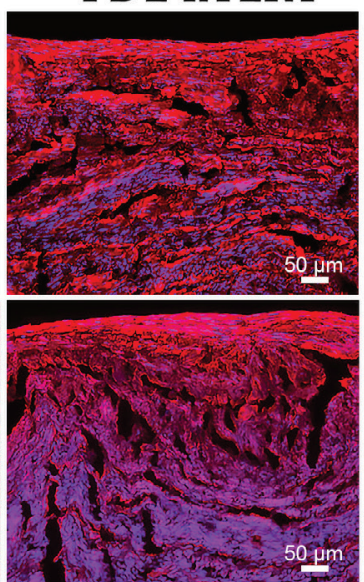

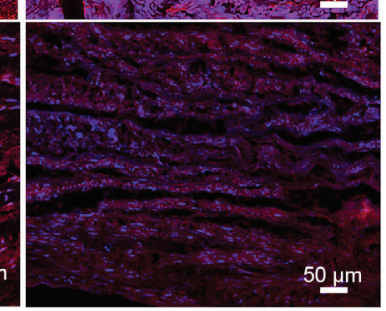

Fig. 6. Gene-expression profile and immunofluorescence staining of the 3D DFC and PDL-hTERT organoids. (a) qRT-PCR analysis of significantly differentially expressed genes. DFC ( $n=6,1$ organoid/ donor) and PDL-hTERT ( $n=1,3$ organoids) organoids. Data are expressed as fold-change to PDL-hTERT. The statistical significance was indicated as ${ }^{* *} p<0.01,{ }^{* *} 0.01<p<0.03$ and ${ }^{*} 0.03<p<0.05$. (b) Representative images of COL 1 and COL 3. (c) Quantitative analysis of COL 1 and COL 3 fluorescent images in DFC ( $n=3$, 1 organoid/donor; 1 section/organoid; 3 images/section; in total 9 mages/group) and PDL-hTERT ( $n=1,3$ organoids; 1 section/organoid; 3 images/section; in total 9 images/group) organoids. Bar graph of mean values and standard deviation of COL-positive area in both groups, each dot represents analysed organoid. The statistical significance was indicated as ${ }^{* *} p<0.01,{ }^{* *} 0.01<p<0.03$ and ${ }^{*} 0.03<p<0.05$. 
comparison of DFCs and PDL-hTERT cells in the self-assembly 3D organoid model, the DFCs exhibit great potential to form a better quality PDL-like tissue mimetics. Despite these promising findings, future studies should cross-compare different engineering strategies. For example, in a direct comparison of PDL cells and DFCs loaded onto barren root chips or synthetic apatite surfaces, the PDL cells showed better anchorage and gene expression, thus behaved superior to the DFCs (Dangaria et al. (2011), suggesting that the two cell types may respond differently to the topography of their environment or may be equipped with different matrix receptors.

A major limitation of this study was the implementation of the immortalised PDL cell line, rather than primary PDL cells. Previous studies demonstrated the PDL phenotype stability of the cell line (Docheva et al., 2010) as well as its successful use as a PDL model in vitro (Ern et al., 2017; Hsieh et al., 2016; Weider et al., 2020). Moreover, the PDL-hTERT cells were capable of forming tendon/ligament-like tissues in vivo when implanted as cell pellets in a rat Achilles tendon defect model (Hsieh et al., 2016). Here, in contrast to DFCs organoids, in the PDLhTERT organoids more columned/clustered cell row arrangement and poorer cell alignment were observed, with larger angular deviation from the organoid long axis. It was assumed that this abnormal cell organisation in the PDL-hTERT organoids might be related to the immortalisation of the cells, which can lead to increase in cell proliferation rather than cell maturation. However, the cell-density investigation did not demonstrate significant differences in DAPIpositive nuclei between the two organoid groups. Hence, further validation, such as quantitative proliferative assays, would be required in future to clarify this speculation. In follow-up studies, it will also be of interest to subject the organoids to various dynamic stretching protocols and to investigate the activation of mechano-responsive signalling cascades. Hence, this PDL 3D organoid model can be implemented for different research questions; for example, understanding relevant molecular signalling in PDL; response to oral pathogens, and assessing the impact and/or side effects of novel oral pharmacologic.

The ultimate purpose of tissue engineeringbased therapy is to replace the injured tissue by a manufactured one. The described self-assembly PDL 3D organoid model has an obvious advantage for possible clinical application in that the engineered tissue mimetic can be directly implanted into the replacement site using a surgical approach. Therefore, it will be of great importance to investigate in future the performance of the DFC organoids in clinically relevant animal models for PDL regeneration (Basu et al., 2019; Guo et al., 2013; Nakahara et al., 2004; Nakashima et al., 2019). For translational study, the most appropriate would be in vivo analyses in large animals since their dental anatomy is closer to human, and several large animal models have been established for periodontal research, such as porcine, ovine or canine (Kantarci et al., 2015). One example is the canine surgical model by Nakahara et al. (2004), comprising of periodontal fenestration defects, which can be filled with the 3D organoid and the regeneration can be evaluated histologically and histomorphometrically at different post-surgery time points.

\section{Conclusion}

That DFCs differentiate towards PDL-like tissue mimetic when using the 3D scaffold-free organoid model was demonstrated. Moreover, DFCs exhibited superior organoid morphology, cell row organisation and angular deviation, as well as higher levels of several ligament-related genes compared to PDLhTERT cell line. Thus, the 3D organoid model could serve as a novel strategy to direct DFC behaviour, which could be further developed in functional PDL engineering application.

\section{Acknowledgements}

D.D acknowledges the financial support of the EU H2020-WIDESPREAD-05-2017-Twinning Grant "Achilles: Overcoming specific weakness in tendon biology to design advanced regenerative therapies" Proposal Nr. 810850. The authors thank Dr. Girish Pattappa for English proof-reading.

\section{References}

Basu A, Rothermund K, Ahmed MN, Syed-Picard FN (2019) Self-assembly of an organized cementumperiodontal ligament-like complex using scaffoldfree tissue engineering. Front Physiol 10: 422. DOI: 10.3389/fphys.2019.00422.

Benatti BB, Silverio KG, Casati MZ, Sallum EA, Nociti FH Jr (2007) Physiological features of periodontal regeneration and approaches for periodontal tissue engineering utilizing periodontal ligament cells. J Biosci Bioeng 103: 1-6.

Berkovitz BK (1990) The structure of the periodontal ligament: an update. Eur J Orthod 12: 51-76.

Bojic S, Volarevic V, Ljujic B, Stojkovic M (2014) Dental stem cells - characteristics and potential. Histol Histopathol 29: 699-706.

Bosshardt DD, Stadlinger B, Terheyden H (2015) Cell-to-cell communication - periodontal regeneration. Clin Oral Implants Res 26: 229-239.

Chen FM, Jin Y (2010) Periodontal tissue engineering and regeneration: current approaches and expanding opportunities. Tissue Eng Part B Rev 16: $219-255$. 
Dangaria SJ, Ito Y, Luan X, Diekwisch TG (2011) Successful periodontal ligament regeneration by periodontal progenitor preseeding on natural tooth root surfaces. Stem Cells Dev 20: 1659-1668.

Diekwisch TG (2016) Our periodontal tissue: a masterpiece of evolution. J Clin Periodontol 43: 320322.

Docheva D, Padula D, Popov C, Weishaupt P, Pragert M, Miosge N, Hickel R, Bocker W, ClausenSchaumann H, Schieker M (2010) Establishment of immortalized periodontal ligament progenitor cell line and its behavioural analysis on smooth and rough titanium surface. Eur Cell Mater 19: 228-241.

Ern C, Berger T, Frasheri I, Heym R, Hickel R, Folwaczny M (2017) Differentiation of hMSC and hPDLSC induced by PGE2 or BMP-7 in 3D models. Prostaglandins Leukot Essent Fatty Acids 122: 30-37.

Felthaus O, Gosau M, Ettl T, Prantl L, Morsczeck C (2014) Migration of human dental follicle cells in vitro. J Periodontal Res 49: 205-212.

Guo S, Guo W, Ding Y, Gong J, Zou Q, Xie D, Chen Y, Wu Y, Tian W (2013) Comparative study of human dental follicle cell sheets and periodontal ligament cell sheets for periodontal tissue regeneration. Cell Transplant 22: 1061-1073.

Guo Y, Guo W, Chen J, Chen G, Tian W, Bai D (2018) Are Hertwig's epithelial root sheath cells necessary for periodontal formation by dental follicle cells? Arch Oral Biol 94: 1-9.

Hernandez-Monjaraz B, Santiago-Osorio E, Monroy-Garcia A, Ledesma-Martinez E, MendozaNunez VM (2018) Mesenchymal stem cells of dental origin for inducing tissue regeneration in periodontitis: a mini-review. Int J Mol Sci 19: 944. DOI: 10.3390/ijms19040944.

Horiuchi K, Amizuka N, Takeshita S, Takamatsu H, Katsuura M, Ozawa H, Toyama Y, Bonewald LF, Kudo A (1999) Identification and characterization of a novel protein, periostin, with restricted expression to periosteum and periodontal ligament and increased expression by transforming growth factor beta. J Bone Miner Res 14: 1239-1249.

Hsieh CF, Alberton P, Loffredo-Verde E, Volkmer E, Pietschmann M, Müller PE, Schieker M, Docheva D (2016) Periodontal ligament cells as alternative source for cell-based therapy of tendon injuries: in vivo study of full-size Achilles tendon defect in a rat model. Eur Cell Mater 32: 228-240.

Hsieh CF, Yan Z, Schumann RG, Milz S, Pfeifer CG, Schieker M, Docheva D (2018) In vitro comparison of 2D-cell culture and 3D-cell sheets of scleraxisprogrammed bone marrow derived mesenchymal stem cells to primary tendon stem/progenitor cells for tendon repair. Int J Mol Sci 19: 2272. DOI: 10.3390/ ijms19082272.

Kantarci A, Hasturk H, Van Dyke TE (2015) Animal models for periodontal regeneration and peri-implant responses. Periodontol 2000 68: 66-82.

Koda N, Sato T, Shinohara M, Ichinose S, Ito Y, Nakamichi R, Kayama T, Kataoka K, Suzuki H, Moriyama K, Asahara H (2017) The transcription factor mohawk homeobox regulates homeostasis of the periodontal ligament. Development 144: 313-320.

Kono K, Maeda H, Fujii S, Tomokiyo A, Yamamoto N, Wada N, Monnouchi S, Teramatsu Y, Hamano S, Koori K, Akamine A (2013) Exposure to transforming growth factor-beta1 after basic fibroblast growth factor promotes the fibroblastic differentiation of human periodontal ligament stem/progenitor cell lines. Cell Tissue Res 352: 249-263.

Liu J, Yu F, Sun Y, Jiang B, Zhang W, Yang J, Xu GT, Liang A, Liu S (2015) Concise reviews: characteristics and potential applications of human dental tissuederived mesenchymal stem cells. Stem Cells 33: 627638.

Luan X, Ito Y, Dangaria S, Diekwisch TG (2006) Dental follicle progenitor cell heterogeneity in the developing mouse periodontium. Stem Cells Dev 15: 595-608.

Morsczeck C, Götz W, Schierholz J, Zeilhofer F, Kühn U, Möhl C, Sippel C, Hoffmann KH (2005) Isolation of precursor cells (PCs) from human dental follicle of wisdom teeth. Matrix Biol 24: 155-165.

Morsczeck C, Reichert TE (2018) Dental stem cells in tooth regeneration and repair in the future. Expert Opin Biol Ther 18: 187-196.

Nakahara T, Nakamura T, Kobayashi E, Kuremoto K, Matsuno T, Tabata Y, Eto K, Shimizu Y (2004) In situ tissue engineering of periodontal tissues by seeding with periodontal ligament-derived cells. Tissue Eng 10: $537-544$.

Nakashima M, Iohara K, Bottino MC, Fouad AF, Nor JE, Huang GT (2019) Animal models for stem cell-based pulp regeneration: foundation for human clinical applications. Tissue Eng Part B Rev 25: 100113.

Oscarsson J, Johansson A (2019) Comment from the editor to the special issue: "Periodontitis: from dysbiotic microbial immune response to systemic inflammation". J Clin Med 8: 1706. DOI: 10.3390/ jcm8101706.

Park CH (2019) Biomaterial-based approaches for regeneration of periodontal ligament and cementum using 3D platforms. Int J Mol Sci 20: 4364. DOI: 10.3390/ijms20184364.

Pattappa G, Schewior R, Hofmeister I, Seja J, Zellner J, Johnstone B, Docheva D, Angele P (2019a) Physioxia has a beneficial effect on cartilage matrix production in interleukin-1 beta-inhibited mesenchymal stem cell chondrogenesis. Cells 8: 936. DOI: 10.3390/cells8080936.

Pattappa G, Zellner J, Johnstone B, Docheva D, Angele P (2019b) Cells under pressure - the relationship between hydrostatic pressure and mesenchymal stem cell chondrogenesis. Eur Cell Mater 37: 360-381.

Poschke A, Krahling B, Failing K, Staszyk C (2017) Molecular characteristics of the equine periodontal ligament. Front Vet Sci 4: 235. DOI: 10.3389/ fvets.2017.00235.

Raju R, Oshima M, Inoue M, Morita T, Huijiao Y, Waskitho A, Baba O, Inoue M, Matsuka Y (2020) 
Three-dimensional periodontal tissue regeneration using a bone-ligament complex cell sheet. Sci Rep 10: 1656. DOI: 10.1038/s41598-020-58222-0.

Romandini M, Baima G, Antonoglou G, Bueno J, Figuero E, Sanz M (2021) Periodontitis, edentulism, and risk of mortality: a systematic review with metaanalyses. J Dent Res 100: 37-49.

Sarrafpour B, Swain M, Li Q, Zoellner H (2013) Tooth eruption results from bone remodelling driven by bite forces sensed by soft tissue dental follicles: a finite element analysis. PLoS One 8: e58803. DOI: 10.1371/journal.pone.0058803.

Saugspier M, Felthaus O, Viale-Bouroncle S, Driemel O, Reichert TE, Schmalz G, Morsczeck C (2010) The differentiation and gene expression profile of human dental follicle cells. Stem Cells Dev 19: 707717.

Sharpe PT (2016) Dental mesenchymal stem cells. Development 143: 2273-2280.

Sowmya S, Chennazhi KP, Arzate H, Jayachandran P, Nair SV, Jayakumar R (2015) Periodontal specific differentiation of dental follicle stem cells into osteoblast, fibroblast, and cementoblast. Tissue Eng Part C Methods 21: 1044-1058.

Spinell T, Saliter J, Hackl B, Unger K, Hickel R, Folwaczny M (2019) In-vitro cytocompatibility and growth factor content of GBR/GTR membranes. Dent Mater 35: 963-969.

Vo TTT, Chu PM, Tuan VP, Te JS, Lee IT (2020) The promising role of antioxidant phytochemicals in the prevention and treatment of periodontal disease via the inhibition of oxidative stress pathways: updated insights. Antioxidants (Basel) 9: 1211. DOI: 10.3390/ antiox9121211.

Weider M, Schröder A, Docheva D, Rodrian G, Enderle I, Seidel CL, Andreev D, Wegner M, Bozec A, Deschner J, Kirschneck C, Proff P, Gölz L (2020) A human periodontal ligament fibroblast cell line as a new model to study periodontal stress. Int J Mol Sci 21: 7961. DOI: 10.3390/ijms21217961.

Xu XY, Li X, Wang J, He XT, Sun HH, Chen FM (2019) Concise review: periodontal tissue regeneration using stem cells: strategies and translational considerations. Stem Cells Transl Med 8: 392-403.

Yamada S, Murakami S, Matoba R, Ozawa Y, Yokokoji T, Nakahira Y, Ikezawa K, Takayama S, Matsubara K, Okada H (2001) Expression profile of active genes in human periodontal ligament and isolation of PLAP-1, a novel SLRP family gene. Gene 275: 279-286.

Yan Z, Yin H, Brochhausen C, Pfeifer CG, Alt V, Docheva D (2020) Aged tendon stem/progenitor cells are less competent to form 3D tendon organoids due to cell autonomous and matrix production deficits. Front Bioeng Biotechnol 8: 406. DOI: 10.3389/ fbioe.2020.00406.

Yan Z, Yin H, Nerlich M, Pfeifer CG, Docheva D (2018) Boosting tendon repair: interplay of cells, growth factors and scaffold-free and gel-based carriers. J Exp Orthop 5: 1. DOI: 10.1186/s40634-0170117-1.

Yang H, Li J, Hu Y, Sun J, Guo W, Li H, Chen J, Huo F, Tian W, Li S (2019a) Treated dentin matrix particles combined with dental follicle cell sheet stimulate periodontal regeneration. Dent Mater 35: 1238-1253.

Yang XT, Ma Y, Guo WH, Yang B, Tian WD (2019b) Stem cells from human exfoliated deciduous teeth as an alternative cell source in bio-root regeneration. Theranostics 9: 2694-2711.

Yao S, Pan F, Prpic V, Wise GE (2008) Differentiation of stem cells in the dental follicle. J Dent Res 87: 767771.

Zhang J, Ding H, Liu X, Sheng Y, Liu X, Jiang C (2019) Dental follicle stem cells: tissue engineering and immunomodulation. Stem Cells Dev 28: 986-994.

Zhou T, Pan J, Wu P, Huang R, Du W, Zhou Y, Wan M, Fan Y, Xu X, Zhou X, Zheng L, Zhou $X$ (2019) Dental follicle cells: roles in development and beyond. Stem Cells Int 2019: 9159605. DOI: $10.1155 / 2019 / 9159605$.

\section{Web References}

1. http://flowingsoftware.btk.fi/index.php?page=3 [25/04/2020]

2. https://imagej.nih.gov/ij/download.html [03/11/2020]

3. https://www.graphpad.com/scientific-software/ prism/ [01/08/2020]

Editor's note: There were no questions from reviewers for this paper; therefore, there is no Discussion with Reviewers section. The Scientific Editor responsible for this paper was Thimios Mitsiadis. 